\title{
Meditation as a kind of leisure: the similarities and differences in the United States
}

\author{
Jaeyeon Choe $^{\mathrm{a} *}$, Garry Chick $^{\mathrm{b}}$ and Michael O’Regan ${ }^{\mathrm{c}}$ \\ ${ }^{a}$ Faculty of Hospitality and Tourism Management, Macau University of Science and \\ Technology, Macao, China; ${ }^{b}$ Recreation Park and Tourism Management, Pennsylvania State \\ University, State College, PA, USA; ${ }^{C}$ Institute for Tourism Studies, Macao, China
}

(Received 28 October 2013; accepted 17 March 2014)

\begin{abstract}
Meditation has been shown to be a cost-effective means to help individuals reduce stress, alleviate anxiety and depression. Similarly, leisure has been found to reduce stress, improve mood and contribute to overall health and well-being. The similarities and differences in outcomes between meditation and leisure suggest that a comparative analysis may determine if and how experiences and outcomes of meditation may be similar to and different from those of leisure and provide deeper insights into the ways in which both can contribute to improved quality of life. The purpose of this study is to examine the similarities and differences in meditation and leisure as perceived by a range of individuals engaging in meditation. Results indicate that meditators experience stress reduction, emotional balance and an enhanced quality of life during both their leisure and meditation. Many of the positive experiences and outcomes derived from meditation render it very similar to leisure. Nevertheless, meditation and leisure also differ in several important ways.
\end{abstract}

Keywords: meditation; stress reduction; emotion management; passive leisure

\section{Introduction}

Organised and folk religions offer a variety of rituals, activities, practices and events that appear to have leisure-like aspects. From various forms and types of pilgrimages, festivals, games, feasts, travel, sports to weddings, funerals and other activities, anthropologists have been interested in religions and how they relate to other aspects of social life. Chick $(1981,1991)$ studied the organisation of the religious festival system in a Mexican village and argued that various religious and ritual activities are 'associated with the performance of dances, the playing of games, feasting and drinking, travel, visiting and other expressive behaviours' (Chick, 1991, p. 1). In traditional rural Mesoamerican villages, religion is 'one of the few systems that provides community-wide recreational services' (Chick, 1991, p. 2). Spiro (1967), when writing about Burmese supernatural religious activities, argued that they provide a leisure-like element for people, noting: 'the holiday mood that accompanies the nat festivals, a mood that is induced in part by all the conditions absent from this local ceremony - respite from labour, the donning of festive clothes, a plenitude of food and drink, and large crowd' (p. 110).

*Corresponding author. Email: jychoe@must.edu.mo 


\section{2 \\ J. Choe et al.}

Chick (1991, p. 4) describes how festival sponsorship activities in Mexico are 'primarily of religious devotion, although it can be argued that religion, as an expressive system, always has intrinsic recreational content'. During the festivals, many recreational activities were held, including festival meals, gaming, horse racing, sports events (baseball, soccer, etc.), fireworks, and were accompanied by ice cream, candy and trinket vendors and sideshows outside the church where ' $[\mathrm{F}]$ ood and alcoholic beverages were consumed in vast quantities' (Chick, 1991, p. 4). Interestingly, the activities around festivals were 'the only form of recreation that is provided on a community wide basis and are the only one to which all community members, young and old, male and female, are welcome' (p. 4). Therefore, religious activities like festivals can contribute to the social life for people and provide community wide recreation and leisure.

Meditation, particularly as practiced in the context of Buddhism, does not, at first glance, seem to be overtly recreational or leisure-like. Nevertheless, we contend that, in terms of both the nature of the experience and outcomes; meditation has some of the qualities of leisure seen in activities associated with religion. The purpose of the study is to determine, first, if, and how, experiences and outcomes of meditation are similar to those of leisure's and, second, how the two are different.

Meditation might be viewed as leisure since meditation getaways are done during free time and of participants own volition. We argue that meditation is also similar to some leisure outcomes and suggest that both meditation and leisure contribute to people's stress reduction and quality of life enhancement. While meditation is not associated with competition, sociability or physical activities, many leisure activities such as playing chess, yoga, gardening, going for a walk, reading, are physically passive, and like meditation, encourage mental activity. While the nexus between leisure and meditation is becoming increasingly visible and apparent, a conceptual discussion linking leisure and meditation is lacking, with a notable shortage of scholarly work directed at Buddhist meditation or related phenomena (Prebish, 1999). Even though news articles (e.g. Dance, 2013; Eastman, 2008; Vora, 2008) occasionally describe meditation as a new leisure style and part of a healthy lifestyle, it needs to be demonstrated with research-based evidence.

While studies about active leisure, such as hiking, canoeing and kayaking are common in major leisure journals, there are relatively few studies about passive leisure, such as television viewing, even though television viewing is a much more common leisure pursuit for North Americans, in terms of time devoted to it, than any other leisure pursuit (e.g. Robinson \& Godbey, 1997). Passive leisure activities such as television viewing, playing video games and shopping are often considered sedentary, individualistic and non-interactive; and it is often described as negative forms of leisure. Historically, however, in East Asian cultures, there are various positive forms of passive leisure activities that have been practiced for thousands of years such as meditation, yoga, Tai-chi, Majiang, tea ceremonies and calligraphy. While research has emphasised the benefits of physical leisure, research has ignored possible positive outcomes of passive leisure with regard to health and well-being (e.g. Caltabiano, 1995; Iwasaki, 2003, 2010). Thus, while creating a conceptual discussion to contribute to our understanding of meditation and its similarities and differences to leisure, the study will also demonstrate some of the benefits of some passive leisure. 


\section{Similar experiences and outcomes between meditation and leisure}

Aristotle said that contemplation is 'one of the two forms of pure leisure (the other being music)' (Neulinger, 1981, p. 7). A growing number of North Americans engage in contemplative activities derived from eastern religions such as yoga and meditation, in order to calm the tensions in their lives (Neulinger, 1981). Meditation fits the definition of leisure, as a freely chosen activity engaged in during one's otherwise unobligated time (without having to be religiously obligated to do so), and has similar outcome qualities.

\section{Stress relief}

Meditation can effectively help patients reduce depression, stress and anxiety. Through meditation practices, including Zen and yoga, people can achieve a deep physiological state of relaxation (Alexander et al. 1993). Meditation practitioners showed 'more relaxed physiological functioning, a greater reduction anxiety, and reduced tension on the job' (Alexander et al., 1993, p. 21). Also, meditation can help people release people's minds from negative emotions and reduce mental activities. Through learned breathing methods, the physical system is encouraged to relax (Layman, 1978).

Similarly, Vegors (1999) argues that healthy individuals are 'aware of their own individual feelings and beliefs, and live these in their lives, rather than solely relying on the environment to tell them how to think and act' (p. 21). Additionally, 'a high percentage of Americans who become interested in Buddhism are drawn to it because of their hope for peace of mind and relief from anxiety, and most who stay with it feel that they have attained those objectives' (Layman, 1978, p. 201).

People who meditate recover from mental and physical illness faster than those who do not and also recover more quickly from negative life events (c.f. Kabat-Zinn et al., 1992, 1995), with one study noting that patients who practiced mindfulness for 10 weeks showed statistically significant reductions in 'present-moment pain, negative body image, inhibition of activity by pain, symptoms, mood disturbance,

30 and psychological symptomatology, including anxiety and depression' (Kabat-Zinn et al., 1984, p 163), whilst 'pain-related drug utilisation decreased and activity levels and feelings of self-esteem increased' (ibid.). A comparison group of pain patients did not show significant improvement on these measures after traditional treatment protocols. A majority of the subjects subsequently reported continued high compli35 ance with the meditation practice.

Similarly, leisure scholars have reported that leisure can be a stress coping resource, whether due to major life events such as divorce, or minor everyday occurrences like being in traffic (Caltabiano, 1994). Iwasaki (2010) indicates that various leisure helps people reduce stress: 'relaxing or recuperating leisure, leisure-time 40 physical activity, outdoor recreation, health tourism, social leisure, spiritual leisure, cultural dancing, pet ownership, leisure "palliative" coping for taking a break/having a time-out, as well as more systematic TR practices' (p. 151). Therefore, individuals may seek social leisure activities for 'informal disclosure of problems, information on alternative ways of looking at a problem and ways of coping with a stressful situ45 ation' (Caltabiano, 1994, p. 28).

One of the unique contributions of leisure as a coping strategy is gaining a sense of self-control, as people have healthier lives when they feel that they have a higher 
sense of control (Haidt \& Rodin, 1999). Stress levels, when related to feelings of control can even affect the immune system (Godby, 2003). People can reduce stress from creating an illusion to control, as optimistic attitudes allow more positive feelings (Godby, 2003). As a consequence, as a 'free-time, non-obligatory' behaviour, leisure may provide opportunities for people to feel empowered (Iwasaki, 2003), and better able to deal with daily difficulties (Kleiber, Hutchinson, \& Williams, 2002).

Finally, an increasing number of leisure studies' scholars argue that spirituality has become an important motivator when people choose how and where to spend free time (Schultz, 2001), noting how nature-based leisure/recreation activities might help individuals reduce stress and achieve spiritual well-being (e.g. Driver, Brown, \& Peterson, 1991; Dustin, 1994; Fox, 1997, 1999; Fredrickson \& Anderson, 1999; Heintzman, 2007a, 2007b, 2008b; Heintzman \& Coleman, 2010; McDonald, 1989; McDonald, Guldin, \& Wetherhill, 1988; Sweatman \& Heintzman, 2004). Outdoor recreation activities also allow people to experience emotions like refreshment, relaxation and adventure (Heintzman, 2010), and 'once a person experiences these positive emotions, the potential to have a more internalised meditative experience is increased' (Heintzman, 2010, p. 75).

\section{Emotion management}

Researchers have found that meditation helps with managing emotions. Emotion management is important because 'extreme emotional disturbances can adversely affect us', (Sapolsky, 2004, p. 3) and many diseases can be caused or made far worse by stress. When people practice meditation, the brain effectively stimulates positive emotions like compassion (Kabat-Zinn, 1994). Ekman (2007) discusses the Buddhist view of emotions, as reaching an awareness to watch oneself creating more emotional control. Ekman argues that if we become aware that an emotion begins to drive our behaviour, we can consciously choose the most 'constructive' reaction to the situation. Fredrickson, Cohn, Coffey, Pek, and Finkel (2008) indicate that meditation regularly allows individuals to enhance opportunities for generating positive emotions by increasing their attention and creating positive relations with themselves and others, and decreasing their self-consciousness. As a result, they become more satisfied with their lives and make positive life changes.

Johnson et al. (2009, p. 499) also reported that meditation may reduce negative psychological symptoms such as 'diminished pleasure', 'diminished motivation' and 'little interest or desire for interpersonal relationships' with help with psychological recovery.

Leisure too can help individuals enhance positive mood, and reduce negative mood (Caltabiano, 1994; Iwasaki, 2003; Kanner, Coyne, Schaefer, \& Lazarus, 1981; Orsega-Smith, Mowen, Payne, \& Godbey, 2004; Stone, 1987), by helping them interpret negative experiences in positive ways (Carver, Scheier, \& Weintraub, 1989). For example, engaging in nature-based recreation can help individuals enhance their mood and reduce stress (Hull \& Michael, 1995). Individuals may improve their moods through a brief moment/form of leisure such as exercise during a lunch break, casual conversation with co-workers or friends or taking a short walk (Hull \& Michael, 1995). Relaxing, enjoyable and meaningful Teisure can allow individuals to have a moment to breathe deeply and just enjoy the activities, which often contributes to developing hopefulness (Kleiber et al., 2002, 2011). 


\section{Different experiences and outcomes between meditation and leisure}

Leisure can help people forget or get away from stressful life events and worry by keeping the mind busy for a brief period. However, it may only have 'short-term value', since it may not enable individuals 'to adjust more completely to the problem' (Kleiber et al., 2011, p. 390). This short-term effect depends on the kind and

10 context of activities, since leisure activities vary in the degree to which they are relaxing. Caltabiano (1994) argues that individuals may take this into consideration when choosing activities in which to participate. Moreover, some scholars point out that engaging in a leisure activity does not always have a positive effect, as some leisure can actually cause stress (Schneider \& Hammitt, 1995). For example, the presence of friends or co-workers may cause stress especially if the activity requires skills a person lacks, when the individuals involved simply do not enjoy each other's company (Caltabiano, 1994; Glover \& Parry, 2008; Iwasaki et al., 2002; Iwasaki \& Mannell, 2000), or when they engage in coerced leisure.

The effects of meditation tend to be long lasting with regard to managing emotions, physiological benefits and developing emotional intelligence (e.g. Kabat-Zinn et al., 1984). Kabat-Zinn et al. (1984) found that 'the majority of subjects reported continued high compliance with the meditation practice as part of their daily lives' (p. 163). On the other hand, Godby (2003) stated that people can reduce stress from creating an illusion of control, which can be a temporary solution for stress relief. Also, meditation can contribute to the development of compassionate emotions (e.g. Ekman, 2007; Fredrickson et al., 2008) which has not demonstrated or reported for other kinds of leisure.

\section{Research questions}

Based on the meditation and leisure literature, I conducted three pilot studies in 30 spring 2009, spring 2010 and July 2010. I also used information from a personal diary written over 2010 and my 2008 Master's research to develop the research questions for this study. Firstly, are there similarities between the experiences and outcomes of meditation and the experiences and outcomes of leisure? If so, what are they? Secondly, are there differences between the experiences and outcomes of med35 itation and leisure? If so, what are they?

\section{Methods}

In determining whether the experiences and outcomes of meditation are similar to and/or different from those of leisure, $\mathrm{I}^{1}$ used a descriptive ethnographic method, using participant observation and formal interviews. While Bernard (2006) notes that ethnography can involve fieldwork, interviews, surveys, archival data, library work and experiments, a researcher should use the methods best suited to what he or she wants to know. Bernard (2006) argues that some studies are impossible to conduct without participant observation. Hence, my participation in rituals, social events and other activities with study participants, which included meditation sessions, allowed me to observe informants, take notes and conduct informal conversations over a four month period during 2010 and 2011. While my data collection period was shorter than most anthropological fieldwork, Bernard (2006) notes that many studies using participant observation can be done in weeks or a few months if the researcher goes 
into a study with clear questions (c.f. Handwerker, 2001). Observational data and data from informal conversations findings were later combined with formal interviews in order to obtain answers to my research questions.

I carried out participant observation in a meditation group in a northeastern US university community and a Zen meditation group in the same community. Meditators at the meditation group and I gradually built trust as they appreciated my contribution to the group as a founding vice-president during the spring semester of 2011. I offered meditation lessons twice a week, held social events, advertised the group and took care of other paper work. Additionally, each Sunday over a five month period, I visited a local Zen centre to participate in meditation and socialise with visitors, practitioners and leaders. Their meditation session includes an hour discussion on meditation practices, an hour sitting and walking meditation in the centre, and another half an hour walking meditation outside in the garden area. Attracting 16-17 people at a time, I meditated with them, and talked with some of them before and/or after the sessions.

Through intensive and long-term interactions with participants, researchers can gain an 'intuitive' understanding about them (Bernard, 2006). It took time and effort to make the participants feel comfortable and close to me. While initially suspicious of me since I was the only Asian and not in their age group, I became less of a curiosity over time life as I volunteered, attended religious rituals, meditation sessions and other social events. As I gained their trust, they helped my research by sharing their life histories. This was consistent with Bernard's notion that once participants trust that the researcher will not betray their confidence, they will have ordinary conversations and ordinary behaviours in his or her presence. Observation was useful when addressing the research questions that request insiders' views about a phenomenon, Bernard (2006) stated that when researchers want to know what participants 'actually do', there is no better way than watching them. As such, I was able to take photos of the meditation groups and social gathering scenes, and the photos helped me analyse data by providing effective visual forms when I wrote field notes. These notes including an objective description of facts, a personal journal and $\hat{a}$ theoretical analysis in order to effectively understand the data.

While the interview data had more details and the field notes contained general information, I brought them together as an ethnography. From interview transcripts and field notes, 450 pages of descriptions were assembled, allowing me to develop a 'thick description' of the phenomenon and search for the multiple and deeper meanings in the data (Bernard, 2006). I looked for the 'significant statements', sentences or quotes that could provide an understanding of how the participants experience certain phenomenon. I placed the data together under each question, such as outcomes of meditation, and similarities and differences between meditation and leisure. I then compared and analysed the participants' perspectives on motivations, benefits and meditating as a leisure experience. Under each topic, I put the closely related quotes and notes, and thus I could visually organise the information. As part of my search for significant statements, I focused on keywords that appeared most frequently in my data-set. The majority of participants said that meditation helps them 'reduce stress and anxiety' and 'slow down.' I also focused on questions and topics that were frequently addressed. Such topics included: (1) the initial interests and motivations - coping strategy/life crisis, spiritual path but not religion and cultural curiosity; (2) quality of life - clearing minds and slowing down, cultivating a frugal lifestyle, being 'present', becoming more compassionate, learning the holistic 
worldview and managing negative emotions; (3) the similarity to leisure - relaxing, freedom or free-ing, experiencing 'flow' and socialising; (4) the differences from leisure - relaxing with alertness, essential/healthy leisure, discipline, structure, effect on other aspects in life or work, leisure for meditation, being woven together, physical exercise, pressure for fun and lasting longer of the effect. From the data, these topics were most frequently mentioned and were based on my literature review, confirmed with the field notes, and developed with the transcripts.

10 I attempted to examine if there were any patterns among the participants, based on the length of practicing meditation or anything else such as their demographic or socio-economic characteristics. While analysing the data, I found that proficient meditators shared similar experiences with respect to their meditation practice as opposed to beginner meditators. For instance, I found that beginner meditators experience or 15 expect different benefits and outcomes from their meditation practices in comparison to proficient meditators. Beginners focused more on just relaxing and having a quiet time away from daily hassles, while proficient meditators focus on cultivating their minds and developing compassionate attitudes. I went back to the field notes and transcripts and looked again, focusing on things most frequently mentioned from each

20 group. I found that meditators who had practiced more than 20 years showed similar tendencies as opposed to meditators who had practiced less than 20 years. I drew a line between proficient and beginning meditators using the 20 years of practice as a mark, except for the exceptional case of a Buddhist monk, whom I placed in the proficient meditators' because he had intensively practiced for 10 years. I created sub-cate25 gories of proficient $(N=6)$ and beginner meditators $(N=10)$, revised my initial literature review and refocused my research questions. I created categorised responses from the two groups to more deeply understand their similarities and differences in their perspectives about their meditation and leisure (Tables 1 and 2).

In accord with Bernard (2006), who wrote that 'since total objectivity is, by definition, a myth' (p. 349), I sought data verification and validity. Using multiple sources of data such as interview transcripts, field notes and a literature review helped me to confirm if participants thought my documentation and interpretation reflected what they wanted to say about their experiences of meditation and leisure. I then reflected upon the concept of crystallisation (Richardson, 2000) that helps represent ways of producing knowledge across multiple points of a phenomenon Crystallisation helped to provide a way of achieving depth, through the compilation of different forms of representing, organising, and analysing details. While Cope (2005) notes that a description of a phenomenon as represented by the researcher

AQ78 Table 1. Characteristics of proficient meditators.

\begin{tabular}{|c|c|c|c|c|c|c|}
\hline & Mr. C & Mrs. B & Mrs. T & Mr. S & Mr. G & Mr. D \\
\hline Gender & Male & Female & Female & Male & Male & Male \\
\hline Age & 32 & 60 & 58 & 63 & 65 & 52 \\
\hline Occupation & Monk & $\begin{array}{l}\text { Zen } \\
\text { priest/ } \\
\text { artist }\end{array}$ & $\begin{array}{l}\text { Meditation teacher/ } \\
\text { English editor for } \\
\text { international } \\
\text { students }\end{array}$ & $\begin{array}{l}\text { Professor } \\
\text { in art } \\
\text { history }\end{array}$ & $\begin{array}{l}\text { Meditation } \\
\text { teacher }\end{array}$ & $\begin{array}{l}\text { Yoga/ } \\
\text { meditation } \\
\text { teacher }\end{array}$ \\
\hline $\begin{array}{l}\text { The length } \\
\text { of practice }\end{array}$ & $\begin{array}{l}10 \\
\text { years }\end{array}$ & 22 years & 32 years & 30 years & $\begin{array}{l}\text { About } \\
30 \text { years }\end{array}$ & $\begin{array}{l}\text { About } \\
22 \text { years }\end{array}$ \\
\hline
\end{tabular}


8 J. Choe et al.

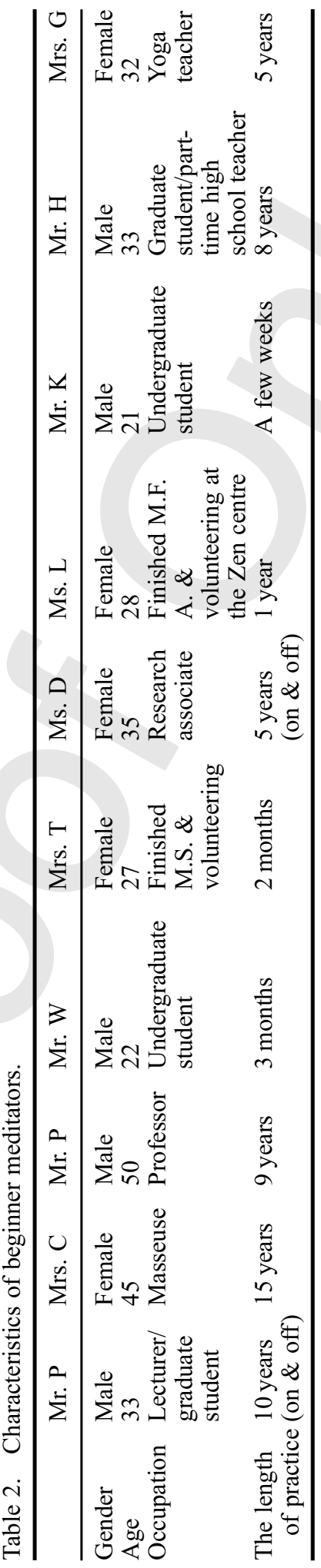


can be a personal interpretation, I discussed the findings and interpretations with participants as part of the validation and verification process. I also talked to key informants regularly about my observations, interpretation and analysis to ensure I did not misrepresent or misunderstood anything. However, given that the study was limited to two Buddhist meditation groups, the results cannot be generalised to the population of meditators in the United States as a whole. Neither can the results be generalised to meditation traditions other than Buddhist, such as Sufi, Jain or even secular meditation.

\section{Results}

\section{Similarities between meditation and leisure}

The majority of participants first became interested in meditation through college courses such as 'Buddhism', 'World Religions', 'Eastern Philosophy' and visiting local Zen centres to begin meditation practices. While spiritual, 13 out of 16 participants did not consider themselves Buddhist or align themselves to any organised religions.

The similarities between meditation and leisure most frequently mentioned were stress reduction and emotion management/mood enhancement.

\section{Stress relief}

All participants mentioned that both meditation and leisure are relaxing. This was in line with my participant observation when at the end of meditation meetings; relaxation and getting the mind off too much thinking were often discussed. One novice participant, for example, does biking, yoga and fixes things around his house for leisure. He said that biking is similar to his meditation practice because, unlike work, there is no specific end. He goes biking without knowing where he will go, but he said that his experience is that he doesn't think much while doing it and is not thinking about anything specific, which relaxes him. The interview data confirmed that:

Meditation should be the most relaxing thing. It may be a bit challenging to get the hang of it. But if one practices, the more one is used to doing it, the more relaxing it becomes, concentration should be done with a relaxed body and mind.

Most participants believe that both meditation and leisure are relaxing. One participant said, 'Exercise makes me relaxed ... when I finish it body is relaxed like meditation ...' Another participant said that kick-boxing is similar to meditation:

I learn all the moves and putting all the moves together into a sequence. I can't really think about anything else ... So I can't think about work when I am there. So, it's almost like meditation. I have to be in the present listening to the instructor and practicing what we are doing. So, kick-boxing has been almost like a meditative thing for 40 me.

Thus, participants perceive that leisure and meditation experiences can be similar because they both provide relaxation. In addition, 'freedom' was often mentioned during the interviews. A monk pointed out the importance of freedom for meditation: 


\section{$10 J$. Choe et al.}

My mind is much less bound up by worry or self-consciousness, or wanting ... so it's much freer ... It's helpful in having freedom from wanting, wanting, wanting ... Eventually, the mind doesn't crave nearly as much for the things.

Buddhist practice is about freedom, freedom from suffering ... there are lots of ways to release suffering.

Similarly, some novice meditators mentioned that they meditate when they feel like it, which is how they also define leisure. Like their leisure, they indicated that they meditate when they have free time or when they want to do it.

Several novice meditators mentioned that they experience an intense concentration - 'can't think of anything else' - while engaging in some leisure activities such as running, playing music and drawing; and draw similarities to their meditation experiences. They get into the activity very deeply with intense concentration without caring about what's happening outside. For example, one novice participant said that playing music is similar to meditation because he can't think of anything else when playing music. Similarly, another participant said:

both music and art and meditation all require certain brain states ... when you play music, you getting to this zone ... so you start playing, and you begin to hear what you are playing ... you feel it, and then becomes black-out ... This cycle of hearing, feeling and playing, and as you keep going further into this music ... forget about everything else. I am getting really close to the present ... It's very close to focus things because you are not thinking about anything. You are not even thinking about playing ...

similar for art ... very focused cuz you have a canvas, or drawing pad ... it's a very clear focus, this is your world ... There is nothing else exists outside this canvas ... I think meditation, how I've been doing it, is similar brain state in that everything else sort of evaporates. But it's more open, it's more blank ... the similarity that you can't be really thinking that much, at least consciously. You just sort of allow your brain to do something. That's why I've been practicing meditation that has been more openawareness.

Participants mentioned that when they engage in some leisure activities for a certain time, they achieve an intense concentration, ensuring that they are not able to think about anything that is happening outside. They perceived that this focus and concentrated state is similar to their meditation experiences.

\section{Emotion management}

Many participants mentioned that they meditate in order to gain the control over their motions. They reported that they like to save energy from negative emotions and the negative consequences that arise from such emotions. They felt that when they stay positive, they can focus on more important things. For example, veteran meditators noted that:

We can transform negative emotions or better yet, cease from generating attachment to thoughts - which leads to emotions of all kinds, negative or positive and free ourselves from being pulled along by emotions then every situation is seen clearly as it is neither negative or positive.

My life has slowed down, become more peaceful and calm (after starting to meditate). I can more easily accept and work with various forms of discomfort - both physical, psychological and emotional. The core of practice is simply to be and to accept everything just as it is. 
You can get a massage. But, the real suffering that causes everything else is the suffering that comes from not really understanding. And knowing who we are, and who we truly are ... we get depressed, we get anxious, we are fearful, or we are angry ... You might think these are the feelings that I have ... I feel tired, I feel sad, I wanna cry, and my heart-ache. Those are my sensations. But 'I am not contained in that.' I am not contained in those. I am everything. I can't be reduced to that to those sensations. I am not that self.

We take the discipline (meditation) in control, if we meditate everyday ... the discipline, control of your emotion ... (meditating) for 15 or $20 \mathrm{~min}$, and then you are already on that path, take control of emotion.

One novice participant also sought control over his emotions to deal with the perceived gap between his ideal self and the reality. It appears that meditation helps people develop greater confidence in themselves so they don't have to dwell too much on people's negative comments, or get affected by high societal expectations. Thus, meditation can contribute to people's psychological health by generating positive emotions, confidence and inner strength, and by decreasing self-consciousness.

\section{Differences between meditation and leisure}

I found there are different qualities between meditation and other kinds of leisure such as physically inactive (i.e. TV viewing) leisure and competitive, sociable and physically active leisure. Some meditators mentioned that 'leisure is more like doing whatever I feel like doing', while meditation requires more discipline, schedules and structures. In addition, whilst like leisure, meditation may affect other aspects of one's life such as relationships and work, other leisure is more to enjoy the moment and escape from short-term worries. Some meditators mentioned that other leisure (i.e. hanging out with friends, getting a massage, having a beer) is a temporary solution from worries and other stressors. Meditation was seen as a long-term solution because meditation deals with problems at a deeper level, and the effects last longer.

\section{Different kinds of relaxation}

30 Even though 'relaxation' is a similar concept shared across meditation and other leisure, additional dimensions regarding the attitude to relaxation emerged. A veteran meditator noted that 'The actual practice of meditation includes relaxation, attention and awareness'. Several veteran meditators emphasised that the kind of relaxation achieved from meditation is different from just relaxing through television viewing or other fun activities because they actively have to work on forgetting negative feelings. For example:

The practice precisely is relaxing and learning about stress, and what causes it. Then one learns to resolve stress, and the internal causes as opposed to escaping some external stress.

Some people see meditation and retreats as kinds of vacations where they just go once in a while to relax and enjoy themselves like going to a spa ... However, those kinds of people aren't able to really get benefits from meditation. They just see it as a kind of external activity that they do to 'get away' or to enjoy themselves for a bit. Then go back to the stress and worry of daily life. That's a 'meditation tourist' attitude, I guess you can call it or 'retreat center tourist'. 


\section{2 \\ $J$. Choe et al.}

All the while trying to maintain a mental state of relaxation yet alertness, calmness yet clarity, as opposed to running here and there to try to get as many pleasant sensations as possible.

Thus, meditators would experience relaxation but with a more alert attitude. If they feel stress, they do not avoid it. Instead, they try to find the reason for it and try to understand the situation. After working on this and practicing, they can feel more relaxed not only when they are meditating but also when they are doing other activities. They pursue relaxation through meditation, but do so focused on creating a healthy lifestyle and mind. Two veteran meditators pointed out that meditation can be considered as a form of healthy or essential leisure because it requires a healthy attitude. For example:

Meditation is an essential practice, not just fun, and not just a way to fix our problems ... going for a massage is a kind of healing leisure. But it doesn't get to the point, whereas meditation and self-reflection are 'essential' leisures that can help us resolve in the midst of stress.

Therefore, like other leisure, one of the benefits of meditation can be relaxation, but it may require individuals to pay more and longer attention to a healthy attitude and alert mind. This is why meditation may require more commitment than leisure and a regular schedule to practice.

\section{Discipline}

Several participants mentioned that leisure is doing something for 'a personal reason,' 'enjoyable,' 'in my own time' and 'for myself.' But, meditation requires more discipline. For example:

The difference would be, for leisure I do whatever I feel like, whereas meditation, at least I am trying to follow some discipline ... I have a deeper commitment to meditation, more commitment than to Elk Creek Café.

Leisure is kind of like when people do things that they like, or to get a kind of enjoyment from doing a hobby. It can be a kind of pleasure seeking. Usually monastics, due to their code of discipline, do not do things like that but rather make use of all time as a way to practice cultivating their minds rather than letting the mind run after something pleasurable or leisurely.

I really want to be more regular about that, more committed ... I know there are gonna be the other people there, so there is kinda accountability thing.

I do it (leisure) for a personal reason in free time. I run, hang out with friends and read. But, they don't require discipline like meditation does, so that's the difference.

Participants emphasised that meditation requires more structure and discipline than other leisure. Additionally, one novice participant shared his experience of achieving the first stage [of seven or eight stages of meditation practice], where he can be in a very peaceful zone under his own control. People may not experience this kind of achievement through their leisure activities because it requires a great amount of mental training and dedication.

Also, in certain traditions like Mahayana or Rinzai Zen, the practice disciplines are strict. When I went to Buddhist temples in Korea (Mahayana), I had to sit on the floor and tolerate [sitting] pain for hours, since 'toleration' is part of the practice. In mindfulness meditation, however, 'relaxation' and taking one's own comfortable 
position and place are central. The meditation leaders would emphasise that meditation should be relaxing and not involve struggling or trying to force anything, but to let the thoughts go, watch, then accept and become interested in those thoughts. Thus, each tradition requires different level of discipline.

In addition to the meditation tradition, the number of years of practice (or even participants' age) and the intensity of practice can affect how much participants can truly and mentally relax. For example, one participant said that he's been meditating for about 10 years. I asked him if the longer you meditate, the easier you can concentrate. He said that it is true and getting older helps. Thus, it seemed that several

10 factors help meditators cultivate their minds and/or achieve deeper levels of relaxation. These include the tradition, the length of practice, participation in long-term retreats and age.

\section{Structure}

I found that some meditators have a structured meditation schedule and these schedules were discussed as a characteristic that differentiated meditation from what they considered leisure. For example, meditation group meetings and sessions have set times in certain places and follow certain rules. These mediators shared their structured meditation practice schedule:

The formal sitting meditation, or any other formal meditation that I do is important usually, sitting in a quiet place, protected, in a shrine. So that's different: a place that happens. And I think most everything else is pretty much the same.

For meditation, I really make it a priority, and I schedule it, whereas I go to the gym-I don't schedule. Maybe I have this intention that I am gonna do it. And I may or may not do it. I may not go to a bike ride, I may not get the book read today, whereas (for) meditation I am making more of like an appointment with myself.

Because it's a certain time of the day, that works for me. Ok, 7:30 Wed, I am with this (meditation) group, will work. I can schedule that ... Maybe I make it more of a priority. I may not cook something that I wanna cook even though I have the time.

Obviously no during the winter (regular gardening). I don't like (to garden) every

One participant, as an academic, feels like he works for seven days a week and constantly thinks about his work and research. Thus, he wants to have a time to block himself off from work and just relax. Another veteran participant said that he wants to make meditation practice a consistent thing 'like exercising' since 'you can't work out once and expect the benefits'. Veteran meditators and meditation teachers advised novice meditators that it is important to set a certain time and place to practice meditation because it creates good energy in time and space. They believe that the accumulated good energy helps us to practice even better.

\section{Effects on other aspects in life}

40 The majority of the participants mentioned that meditation affects their life and work. Some novice meditators mentioned that it is not about spending time on meditation, but more like investing time because of the constructive outcomes for their life and work. One novice participant said that: 


\section{4 $J$. Choe et al.}

... when I meditate on a regular basis, it's easier to simply stay with the fish to just eat and to enjoy. Also, it helps me concentrate and to respond to things rather than just react. Furthermore, meditation relaxes me ... to slow things down and clear my head. It slows me down and helps me take things a little less seriously ... When I'm meditating on a regular basis, I also can usually remain centered when these things happen. I don't get so caught up.

As opposed to this, several novice and veteran meditators noted that hanging out with friends, laughing with them, doing drugs, drinking and just keeping busy with activities which might seem like other leisure only offer a temporary solution. For example:

They look for that (getting away from difficulties) in drugs, in alcohol, or in entertainment, in filling up their planner ... in all kinds of distractions to fill that feeling.

People develop the ways of tricking themselves? Make them think it's gone away. So, let's say you are frightened. You say, just have a beer. Or, how about I go out with friends and we will laugh, and forget about it. But it really hasn't gone away. Will come up again ... so it's like we all develop temporary solution.

Most of the participants including novice and veteran meditators also mentioned that with their clearer and more focused minds, they can make better decisions and see more things more clearly (i.e. solutions and strategies). They also note that their lives (or things) go more smoothly when they regularly meditate because they have clearer and calmer minds. One novice participant often felt tired and sleepy but after meditation, always feels more energised:

I planned to go home straight after meditation, but I actually decided to get more work done before going home.

If I just take the time, then I think I am more efficient. As far as time, it pays off ...

As investment whereas spending time ...

Furthermore, several meditators including novice and veteran mentioned that calming down and clearing their minds help them be more efficient at work. They see the time for meditating as a good investment as it pays off in a practical way.

\section{Discussion}

The field notes, transcript data and literature suggest that both meditation and leisure can help people with stress reduction, emotion management and health. Like leisure, which involves 'perceived freedom' and 'an internal locus of control' (Godbey, 2008), similar goals such as freeing the mind and emotional control exist. Study participants noted that meditation and leisure are both 'just for me' and 'my own time'. Meditation practice encouraged them to transfer negative emotions into positive ones; leisure gave them to take a break from stressful situations and interpret negative experiences in a positive way. They expressed the belief that both meditation and leisure provide opportunities for getting away from daily hassles/burdens, whilst enhancing positive moods and reducing negative moods.

However, participants noted differences between meditation and physically active /inactive leisure. While meditation has its own purpose for informants, such as goals like wisdom and compassion, it also requires discipline and structure. Some participants perceive meditation practice as an essential activity, mentioning that other leisure is more like doing whatever they feel like doing. Even though 'relaxation' as a 
quality is similar to meditation and leisure, experienced meditators note that the kind of relaxation brought about through meditation requires more attention and a calmer attitude. Through their meditation practice, they believe that they can find stress sources and deal with it at a deeper level instead of avoiding it by occupying their time with other kinds of leisure. In this way, people can even achieve 'higher level' of freedom by cultivating the mind. As a consequence, participants point out that the effects of meditation last longer because it solves problems, with other leisure not enabling individuals to solve the problem completely. Informants noted that leisure only helps them to temporarily forget or get away from stressful life events and worry. Unlike meditation practice, engaging in a leisure activity also does not always help them reduce stress, as some leisure (i.e. overly competitive or coerced

15 leisure) can actually cause stress. Therefore, meditation can help people understand how to use their unoccupied time as a healthy form of leisure. These positive effects can last as long as their life time depending on their practice is a sustained effort.

As well as the difference between meditation and other leisure, the meditation experience for beginners and veterans differed. Inexperienced meditators reported

20 that meditation can be calming and relaxing, and enjoy the quiet time alone, but it also requires hard work because they have to consciously concentrate. On the other hand, experienced meditators are interested in achieving higher level of freedom and complete relaxation from worries, thoughts and other external environments. They also focus on cultivating their minds by deep observation, and actively integrating

25 meditation methods into their lives in both work and leisure. Thus, instead of blocking some time to be quietly alone and relax, they are actively working on achieving the complete control over their life to be free from external factors. They express how they have become content with their lives and how their meditation practice affects their lives in positive ways. Experienced meditators argue that meditation,

30 leisure and work are not separate, but woven together within a meditative attitude. They believe any leisure can be part of their meditation practice.

\section{Conclusions}

Religious activities can contribute to the social life and provide community-wide recreation and leisure. There is increasing evidence that peoples' spiritual experi35 ences may contribute to spiritual health, stress reduction, intellectual growth, selfactualisation, meta-physical consciousness and cultural awareness. Leisure scientists have not paid enough attention to passive leisure activities, even though passive leisure is extremely common. While many studies about active leisure, such as hiking, canoeing and kayaking are published in major leisure journals, those studies related 40 to passive leisure, such as television viewing is rare, even though it is a much more common leisure activity in the US. Further research into passive leisure activities that investigate both negative and positive outcomes with regard to health may demonstrate some of the benefits of passive leisure.

In adding to our understanding of passive leisure literature, this study can contribute to the theory of serious leisure (Stebbins, 1982). As many Americans engage in meditation for non-religious reasons, serious leisure may be relevant to future discussions regarding meditation. This is primarily because meditation requires a special practice or certain technique that puts it closer to serious rather than casual leisure. 


\section{$16 J$. Choe et al.}

In addition to these theoretical contributions, this study shows how meditation is influencing values and lifestyles in the US. It is important to note that engaging in meditation may not only provide relaxation, mental well-being or spiritual fulfilment, but also may allow people to learn about simple and frugal lifestyles. It is also a new option for those seeking an effective and cost-efficient stress coping strategy. As people can meditate at home and at their convenience, it can contribute to quality of life, which connects with multiple perspectives on leisure. Since meditation practices are recognised as strategies for managing stress and emotions, local or commercial recreation organisations might offer meditation classes to people who are interested in reducing stress and anxiety with lower costs.

\section{Future recommendations}

- The current study suggests meditation is a form of passive leisure, with perceived benefits. This study employs a new lens through which to examine positive experiences and outcomes derived from meditation that renders it similar to leisure. Further research in the future may involve the following: Leisure scholars need to pay more attention to how religion or religious activities may provide leisure-like qualities to people and society.

- Passive leisure needs to be further explored to expand the literature and develop a deeper understanding about leisure. In addition, the benefits and positive roles of passive leisure are needed to be recognised. Meditation, in particular, should be further explored, with particular emphasis on physiological, emotional, social and intellectual effects, and the increasing number of North Americans engaging in meditation. Leisure scholars have over focused on western contexts or preferences of leisure activities, while ignoring eastern philosophical or cultural leisure activities, and other culturally diverse leisure phenomena.

- There is a need to study how veteran meditators define leisure as opposed to beginning meditators, and how meditation, as a form of leisure helps improve perceived quality of life.

- I defined proficient meditators as those had practiced more than 20 years with daily/intense practice. However, one proficient meditator indicated that he thinks the experience of an intensive meditation event like 10 day-long retreat is very important to be a proficient meditator as it provides a different level of the meditation experience such as deeper cultivation of the mind. I did not closely examine this as most of my participants had not been on this kind of intensive retreat, but in future research, this can be added given my definition of experienced or proficient meditators remains vague and underexplored.

- I used a descriptive method to provide more depth. It was incomplete and static, since analysis was based on the frequency of the concepts. Thus, quantitative techniques could be added for more ethnographic data, with more systematic data analysis. In addition, a longer participant observation study may contribute to provide better and deeper data about this phenomenon.

1. 'I' refers to the first author. 


\section{Notes on contributors}

Jaeyeon Choe teaches Leisure Management and Entertainment Tourism at Macau University of Science and Technology. She has published her research work using both qualitative and quantitative approaches in SSCI journals. She has actively presented her papers related leisure and meditation; issues of Chinese leisure at several international conferences in Ireland, Italy, Spain, USA, and Malaysia. She has led small research projects with colleagues in the United States, Netherlands, Korea as well as China.

Garry Chick is a professor at Pennsylvania State University. He gained Ph.D. in Anthropology at University of Pittsburgh. His research interests are leisure and culture; leisure, culture \& health, the culture-behaviour relationship, and play theory. He teaches Leisure and Culture at Penn State. He has numerous publications in leisure studies field.

Michael O'Regan worked alongside the National Tourism Development Authority of Ireland when he joined Gulliver - Ireland's Information and Reservation Service in 1997 after he completed his two-year research Masters at the University of Limerick. He joined Wicklow County Tourism, Ireland as Marketing Executive in 1997 for three years before starting a $\mathrm{Ph} . \mathrm{D}$. programme at the School of Sport and Service Management, University of Brighton, UK which he completed in 2011. He currently teaches Event Management at Institute for Tourism Studies in Macao, China.

\section{References}

Aldwin, C. M. (1994). Stress, coping and development: An integrative perspective. New York, NY: The Guilford Press.

Alexander, C. N., Swanson, G. C., Rainforth, M. V., Carlisle, T. W., Todd, C. C., \& Oates, R. M. (1993). Effects of the transcendental meditation program on stress reduction, health, and employee development: A prospective study in two occupational settings. Anxiety, Stress \& Coping, 6, 245-262.

Bernard, R. H. (1994). Research methods in anthropology: Qualitative and quantitative approaches (2nd ed.). Thousand Oaks, CA: Sage Publications.

Bernard, R. H. (2006). Research methods in anthropology: Qualitative and quantitative approaches (4th ed.). Langam, MD: Altamira Press.

Bolger, N., \& Eckenrode, J. (1991). Social relationships, personality, and anxiety during a major stressful event. Journal of Personality and Social Psychology, 61, 44-449.

Brown, J. D. (1991). Staying fit and staying well: Physical fitness as a moderator of life stress. Journal of Personality and Social Psychology, 60, 555-561.

Brown, G. W., \& Harris, T. (1978). Social origins of depression: A study of psychiatric disorder in women. New York, NY: Wiley.

Caltabiano, M. L. (1988). The effect of predisposing variables and leisure on the relationship between stressful life events and illness symptomatology (Unpublished doctoral dissertation). James Cook University, Townsville. Société/Society and Leisure, 18, 33-51.

Caltabiano, M. L. (1994). Measuring the similarity among leisure activities based on a perceived stress-reduction benefit. Leisure Studies, 13, 17-31.

Carlson, L. E., Speca, M., Patel, K., \& Goodey, E. (2003). Mindfulness-based stress reduction in relation to quality of life, mood, symptoms of stress, and immune parameters in breast and prostate cancer outpatients. Psychosomatic Medicine, 65, 571-581.

Carlson, L. E., Ursuliak, Z., Goodey, E., Angen, M., \& Speca, M. (2001). The effects of a mindfulness meditation-based stress reduction program on mood and symptoms of stress in cancer outpatients: 6-month follow-up. Supportive Care in Cancer, 9, 112-123.

Carver, C. S., Scheier, M. F., \& Weintraub, J. K. (1989). Assessing coping strategies: A theoretically based approach. Journal of Personality and Social Psychology, 56, 267-283.

Chick, G. E. (1981). Concept and behavior in a Tlaxcalan Cargo Hierarchy. Ethnology, 20, $217-228$. 
Chick, G. E. (1991). Acculturation and community recreation in rural Mexico. Play \& Culture, 4, 185-193.

Chick, G. E. (1997). Cultural complexity: The concept and its measurement. Cross-cultural Research, 31, 275-307.

Chick, G. E. (2009a, December 21). Personal communication.

Chick, G. E. (2009b, November 22). Personal communication.

Choe, J. (2008). The motivations of non-Buddhists visiting a Buddhist Temple (Unpublished master's thesis). California State University, Long Beach.

Coleman, D., \& Iso-Ahola, S. E. (1993). Leisure and health: The role of social support and self-determination. Journal of Leisure Research, 25, 111-128.

Cope, J. (2005). Researching entrepreneurship through phenomenological inquiry: Philosophical and methodological issues. International Small Business Journal, 23, 163-189.

Driver, B. L., Brown, P. J., \& Peterson, G. L. (1991). Benefits of Leisure. State College, PA: Venture Publishing.

Driver, B. L., \& Tocher, S. R. (1975). Toward a behavioral interpretation of recreational engagements, with implications for planning. In B. L. Driver (Ed.), Elements of outdoor recreation planning (pp. 9-28). Ann Arbor, MI: University of Michigan Press.

Dunkel-Schetter, C., Feinstein, L. G., Taylor, S. E., \& Fakle, R. L. (1992). Patterns of coping with cancer. Health Psychology, 11, 79-87.

Dustin, D. (1994). Managing public lands for the human spirit. Parks and Recreation, 29, 92-96.

Eastman, J. (2008, June 12). Buddhamania: The religious symbol as decoration? It's complicated. Los Angeles Times. Trends section, Print edition.

Ekman, P. (2007). Emotions revealed: Recognizing faces and feelings to improve communication and emotional life (2nd ed.). New York, NY: Owl Books.

Folkman, S., \& Moskowitz, J. T. (2000). Positive affect and the other side of coping. American Psychologist, 55, 647-654.

Folkman, S., Moskowitz, J. T., Ozer, E. M., \& Park, C. L. (1997). Positive meaningful events and coping in the context of HIV/AIDS. In B. H. Gottlieb (Ed.), Coping with chronic stress (pp. 293-314). New York, NY: Plenum Press.

Fox, K. M., \& Klaiber, E. (2006). Listening for a leisure remix. Leisure Sciences, 28, 411430.

Fredrickson, B. L., Cohn, M., Coffey, K. A., Pek, J., \& Finkel, S. M. (2008). Open hearts build lives: Positive emotions, induced through loving-kindness meditation, build consequential personal resources. Journal of Personality and Social Psychology, 95, 10451062.

Freysinger, V. J., \& Flannery, D. (1992). Women's leisure: Affiliation, self-determination, empowerment and resistance? Society and Leisure, 15, 303-322.

Godbey, G. (2008). Leisure in your life: New perspectives. State College, PA: Venture.

Godbey, G. C., Caldwell, L. L., Floyd, M., \& Payne, L. L. (2005). Contributions of leisure studies and recreation and park management research to the active living agenda. American Journal of Preventive Medicine, 28, 150-158.

Godby, G. (2003). Leisure in your life: New perspectives. State College, PA: Venture Publishing.

Guest, G., Bunce, A., \& Johnson, L. (2006). How many interviews are enough? An experiment with data saturation and variability. Field Methods, 18, 59-82.

Haidt, J., \& Rodin, J. (1999). Control and efficacy as interdisciplinary bridges. Review of General Psychology, 3, 317-337.

Handwerker, W. P. (2001). Quick ethnography: A guide to rapid multi-method research. Walnut Creek, CA: Altamira Press.

Heintzman, P. (2002). A conceptual model of leisure and spiritual well-being. Journal of Park and Recreation Administration, 20, 147-169.

Heintzman, P. (2009). The spiritual benefits of leisure. Leisure/Loisir, 33, 419-445.

Heintzman, P., \& Coleman, K. M. (2010). Leisure and spiritual health. In L. Payne, B. Ainsworth, \& G. Godbey (Eds.), Leisure, health, and wellness: Making the connections. State College, PA: Venture Publishing. 
Heintzman, P., \& Mannell, R. C. (1999). Leisure-style and spiritual well-being. In W. Stewart \& D. Samdhal (Eds.), Abstracts from the 1999 symposium on leisure research (pp. 68. Ashburn, VA: National Recreation and Park Association.

Heintzman, P., \& Mannell, R. C. (2003). Spiritual functions of leisure and spiritual wellbeing: Coping with time pressure. Leisure Sciences, 25, 207-230.

Henderson, K. A., \& Bialeschki, M. D. (1991). A sense of entitlement to leisure as constraint and empowerment for women. Leisure Sciences, 12, 51-65.

Ho, J. T. S. (1996). Stress, health and leisure satisfaction: The case of teachers. The International Journal of Educational Management, 10, 41-50.

Hull, R. B., IV, \& Michael, S. E. (1995). Nature-based recreation, mood change, and stress restoration. Leisure Sciences, 17, 1-14.

Iso-Ahola, S. E. (1990). Motivations for leisure. In E. L. Jackson \& T. L. Burton (Eds.), Understanding leisure and recreation: Mapping the past, charging the future (pp. 247279). State College, PA: Venture Publishing.

o-Ahola, S. E., \& Mannell, R. C. (2004). Leisure and health. In J. T. Haworth \& A. J. Veal (Eds.), Work and leisure (pp. 184-199). London: Routledge.

Iwasaki (2003). Roles of leisure in coping with stress among university students: A repeatedassessment field study. Anxiety, Stress, and Coping, 16, 31-57.

Iwasaki, Y. (2007). Leisure and quality of life in an international and multicultural context: What are major pathways linking leisure to quality of life? Social Indicators Research, $82,233-264$.

Iwasaki, Y., MacKay, K. J., Mactavish, J. B., Ristock, J., \& Barlett, J. (2006). Voices from the margins: Stress, active living, and leisure as a contributor to coping with stress. Leisure Sciences, 28, 163-180.

Iwasaki, Y., Mactavish, J. M., \& MacKay, K. (2005). Building on strengths and resilience: Leisure as a stress survival strategy. British Journal of Guidance and Counseling, 33, $81-100$.

Iwasaki, Y., \& Mannell, R. C. (2000). Hierarchical dimensions of leisure stress coping. Leisure Sciences, 22, 163-181.

Iwasaki, Y., \& Schneider, I. E. (2003). Leisure, stress, and coping: An evolving area of inquiry. Leisure Sciences, 25, 107-113.

Iwasaki, Y., Zuzanek, J., \& Mannell, R. C. (2001). The effects of physically active leisure on stress-health relationships. Canadian Journal of Public Health, 92, 214-218.

Iwasaki, Y., Mannell, R. C., Smale, B. J. A., \& Butcher, J. (2005). Contributions of leisure participation in predicting stress coping and health among police and emergency response services workers. Journal of Health Psychology, 10, 79-99.

Johnson, D. P., Penn, D. L., Fredrickson, B. L., Meyer, P. S., Kring, A. M., \& Brantley, M. (2009). Loving-kindness meditation to enhance recovery from negative symptoms of schizophrenia. Journal of Clinical Psychology, 65, 499-509.

Kabat-Zinn, J. (1994). Wherever you go, there you are: Mindfulness meditation in everyday life. New York, NY: Hyperion.

Kabat-Zinn, J., Lipworth, L., \& Burney, R. (1984). The clinical use of mindfulness meditation for the self-regulation of chronic pain. Journal of Behavioral Medicine, 8, 163-190.

Kabat-Zinn, J., Massion, A. O., Kristeller, J., Peterson, L. G., Fletcher, K. E., Pbert, L., ... Santorelli, S. F. (1992). Effectiveness of a meditation-based stress reduction program in the treatment of anxiety disorders. American Psycyhiatric Association, 149, 936-943.

Kanner, A. D., Coyne, J. C., Schaefer, C., \& Lazarus, R. S. (1981). Comparison of two modes of stress measurement: Daily hassles and uplifts versus major life events. Journal of behavioral Medicine, 4, 1-39.

Kleiber, D. A. (1999). Leisure experience and human development. New York, NY: Basic Books.

Kleiber, D. A., Hutchinson, S. L., \& Williams, R. (2002). Leisure as a resource in transcending negative life events: Self-protection, self-restoration, and personal transformation. Leisure Sciences, 24, 219-235.

Kleiber, D. A., Walker, G., \& Mannell, R. C. (2011). Social Psychology of Leisure (2nd ed.). State College, PA: Venture Publishing. 


\section{$20 J$. Choe et al.}

Langer, E., \& Rodin, J. (1976). The effects of choice and enhanced personal responsibility for the aged: A field experiment in an institutional setting. Journal of Personality and Social Psychology, 34, 191-198.

Layman, E. M. (1978). Buddhism in America. Chicago, IL: Nelson-Hall.

Lazarus, R. S., \& Folkman, S. (1984). Stress, appraisal and coping. New York, NY: Springer.

Lazarus, R. S., Kanner, A. D., \& Folkman, S. (1980). Emotions: A cognitive-phenomenological analysis. In R. Plutchik \& H. Kellerman (Eds.), Theories of emotion (pp. 189-217). New York, NY: Academic Press.

AQ64

Mannell, R. C. (2007). Leisure, health and well-being. World Leisure Journal, 3, 114-128.

McDonald, B. L., \& Schreyer, R. (1991). Spiritual benefits of leisure participation and leisure settings. In B. L. Driver, P. J. Brown, \& G. L. Peterson (Eds.), Benefits of Leisure (pp. 179-194). State College, PA: Venture Publishing.

Miller, J., Fletcher, K., \& Kabat-Zinn, J. (1995). Three year follow-up and clinical implications of a mindfulness meditation-based stress reduction intervention in the treatment of anxiety disorders. General Hospital Psychiatry, 17, 192-200.

Morris, W. M., Leung, K., \& Lickel, B. (1999). Views from inside and outside: Integrating emic and etic insights about culture and justice judgment. Academy of Management Review, 24, 781-796.

Neulinger, J. (1981). Leisure lack and the quality of life: The broadening scope of the leisure professional. Leisure Studies, 1, 53-63.

Orsega-Smith, E., Mowen, A. J., Payne, L. L., \& Godbey, G. (2004). The interaction of stress and park use on psycho-physiological health in older adults. Journal of Leisure Research, $36,232-256$.

Prebish, C. S. (1999). Luminous Passage: The practice and study of Buddhism in America. University of California Press.

Prebish, S. P., \& Keown, D. (2010). Introducing Buddhism (2nd ed.). New York, NY: Routledge.

Reyes-García, V., Godoy, R., Vadez, V., Ruíz-Mallén, I., Huanca, T., Leonard, W. R., et al. (2009). The pay-offs to sociability. Do solitary and social leisure relate to happiness? Human Nature: An Interdisciplinary Biosocial Perspective, 20, 431-446.

Robinson, J., \& Godbey, G. (1997). Time for life: The surprising ways Americans use their time. University Park, PA: The Pennsylvania State University.

Rook, K. S. (1987). Social support vs. companionship: Effects on life stress, loneliness, and evaluations by others. Journal of Personality and Social Psychology, 52, 1132-1147.

Sapolsky, R. M. (2004). Why Zebras don't get ulcers: The acclaimed guide to stress, stressrelated diseases, and coping (3rd ed.). New York, NY: Henry Holt and Company.

Schneider, I. E., \& Hammitt, W. E. (1995). Visitor response to on-site recreational conflict: A conceptual approach. Leisure Sciences, 17, 223-234.

Schulz, J. (2001). The window through which we view the world: The association of religion and the meaning of leisure in contemporary Australia (Unpublished dissertation). Griffith University.

Smith, T. W. (2002). Religious diversity in America: The emergence of Muslims, Buddhists, Hindus, and others. Journal for the Scientific Study of Religion, 41, 577-585.

Spiro, M. E. (1966). Religion: Problems of definition and explanation. In M. Banton (Ed.), Anthropological approaches to the study of religion (pp. 85-125). London: Tavistock Publications.

Spiro, M. E. (1967). Burmese supernaturalism. NJ: Transaction Publisher.

Stone, A. A (1987). Event content in a daily survey is differentially associated with concurrent mood. Journal of Personality and Social Psychology, 52, 56-58.

Vegors, S. (1999). Developing psychological health with transcendental meditation. Alternative health practitioner, $5,19-22$.

Vora, S. (2008, December 12). The simple life: Results from New York Times. http:// travel.nytimes.com/2008/12/12/travel/escapes/12ashrams.html.

Woolfolk, R. (1975). Psychophysiological correlates of meditation. Archives of General Psychiatry, 32, 1326-1333. 